\title{
Huacapune: paisaje sagrado y arquitectura en el cerro Tomapongo
}

\author{
Huacapune: sacred landscape and architecture in the Tomapongo \\ mountain
}

\author{
Luigi Mazzi Pflucker \\ https://orcid.org/o0oo-0003-4095-504X \\ Universidad Nacional Mayor de San Marcos \\ mazzilg1@gmail.com \\ José Antonio Bazán Castillo \\ https://orcid.org/oooo-0003-2579-4698 \\ Universidad Nacional Mayor de San Marcos \\ jbc07057@gmail.com
}

\section{RESUMEN}

La presente investigación expone algunas observaciones relacionadas al sitio arqueológico Huacapune, como parte de los resultados preliminares de una serie de reconocimientos de las estructuras prehispánicas ubicadas en el cerro Tomapongo, perteneciente a la cadena montañosa de la "Meseta de Markawasi". El cual es abordado desde un análisis in situ, en base a una perspectiva post-procesual, la cual resultó provechosa para correlacionar, comparar y valorar los tópicos presentes en el área, que contiene temas relacionados con un acervo cultural mítico, evidenciado en los relatos de documentos pertenecientes al siglo XV y visible aun en los segmentos arquitectónicos antiguos, que corresponderían a espacios sagrados aun por conocer y se encuentran en la actualidad formando parte un paisaje vulnerable. A partir de lo expuesto, se intentará rescatar el significado social plasmado en tal ma- 
terialidad, como parte de una aproximación al conocimiento de dicho patrimonio cultural arqueológico perteneciente a la provincia de Huarochirí.

Palabras clave: Huarochirí, Huacapune, paisaje sagrado.

\section{ABSTRACT}

This research presents some observations related to the Huacapune archaeological site, as part of the preliminary results of a series of reconnaissance of the pre-Hispanic structures located on the Tomapongo hill, belonging to the mountain chain of the "Markawasi Plateau", which is approached from an in situ analysis, based on a post-procedural perspective, which was useful for correlating, comparing and evaluating the topics present in the area, which contains themes related to a mythical cultural heritage, evidenced in the accounts of documents belonging to the XV century and visible even in ancient architectural segments, which would correspond to sacred spaces yet to be known and are currently forming part of a vulnerable landscape. Based on the above, an attempt will be made to rescue the social meaning embodied in such materiality, as part of an approach to the knowledge of said archaeological cultural heritage belonging to the province of Huarochirí.

Keywords: Huarochiri, Huacapune, sacred landscape.

RECIBIDO: 28/06/2021 - ACEPTADO: 14/08/2020 - PublicADO: 25/11/2021

\section{INTRODUCCIÓN}

El reconocimiento realizado al sitio arqueológico Huacapune, se debió a nuestra curiosidad como estudiantes en los cursos de pregrado, en la Escuela Profesional de Arqueología de la Universidad Nacional Mayor de San Marcos, que se reforzó con las clases impartida por los profesores en las aulas. Luego se concretaría en exposiciones impartidas, como las llevadas a cabo en el Coloquio de Estudiantes de Arqueología de la Pontificia Universidad Católica del Perú en el año 2014 y en diversas presentaciones en reuniones con colegas interesados en el paisaje cultural y natural de la provincia de Huarochirí. A partir de lo mencionado, el presente trabajo inicialmente se realizó con la intención de documentar, a partir de un primer vistazo, al aprovechamiento de los elementos geográficos en esta área, por lo cual el emplazamiento de estructuras en la cima del cerro Tomapongo, ubicado en el distrito de San Jerónimo de Surco, causó nuestra admiración por la peculiar forma que posee esta cima y la disposición espacial de diversos restos arquitectónicos que fueron modelando aquel espacio, el cual al llegar a su cima, está ordenada en torno al peñón de un cerro. Más allá de la mitificación exótica que cautiva y se le pueda adherir para tratar este tema y en especial si consideramos lo cautivante del 
paisaje y las historias en torno a ella. Nuestra documentación que aventuradamente tuvo por objetivo realizar determinados reportes a partir de descripción del paisaje sagrado huarochirano, encontraría en el análisis de aquellos elementos y componentes arquitectónicos del sitio arqueológico Huacapune, el punto de partida para discutir y formularnos determinadas interrogantes como las correspondientes a las actividades rituales en torno a estos sitios documentados, mencionadas en los documentos históricos, esencialmente en los descritos por los relatos como el de "Dioses y Hombres de Huarochiri" (Taylor, 1999) y "Huallallo, ceremonias gentilicias desarrolladas en la maseta cisandina del Perú. Distrito arqueológico de Casta" (Tello, 1923), cuyo marco nos permitiría generarnos una visión más general de lo ocurrido en el área en tiempos prehispánicos. Por lo tanto, la presente investigación buscar contrastar determinados significados expuestos en la literatura, que posiblemente aún estaban inherente en aquellos espacios del mencionado sitio arqueológico, el cual hasta donde teníamos conocimiento ya tenía elementos destacado por los aventureros que hasta hoy en día visitan el lugar por deporte, como también por breves relatos interesantes de investigadores que conocieron el lugar y por las descripciones que aun podíamos dar a conocer a partir de nuestro reconocimiento. Por ende, nosotros decidimos no quedarnos en la explicación de aquellas estructuras tan solo para un reporte, sino acercarnos a una explicación más humana, que permita sobre todo reconocer a los ocupantes Huarochiranos de los tiempos prehispánicos y explicar las posibles ideas que los llevaron a edificar tales construcciones en lugares tan inaccesibles, aún hoy en la actualidad, es así que para la comprensión de aquello señalado líneas arriba, esbozaremos algunos aspectos previos que nos encaminarán a dichas aproximaciones.

\section{APRECIACIONES GEOGRÁFICAS}

En lo que respecta a la geografía formal. El sitio arqueológico Huacapune se encuentra emplazado en la cima del cerro Tomapongo, el cual es parte de la cadena montañosa conocida como la "Meseta de Markawasi". Su ubicación exacta es : Norte- $8688286.56 \mathrm{~m}$, este-342218.84 m. Datum WGS84, la altura sobre el nivel del mar estimado es: 3650 . La cadena montañosa presenta elementos geográficos interesantes, ya sean lagos, glaciares y el peculiar clima de la zona, que por su verticalidad va desde la Chaupiyunga, zona Quechua y la zona Suní, por lo que su clima va desde los días despejados y secos, al intemperismo propio de la región quechua como las lluvias, granizadas, la niebla, etc. (Figura 1).

Por la configuración topográfica el relieve de la zona es dominantemente inclinada, con escasas áreas de relieve suave. Presenta tres paisajes: Llanura fluvial, Llanura aluvial de pie de monte y Montañas y colinas. Con respecto al clima se caracteriza por ser una zona templada húmeda con invierno seco y verano templado. Asimismo, tiene una media anual en precipitación de $300 \mathrm{~mm}$ y una temperatura de $15.6^{\circ} \mathrm{C} .45$. 


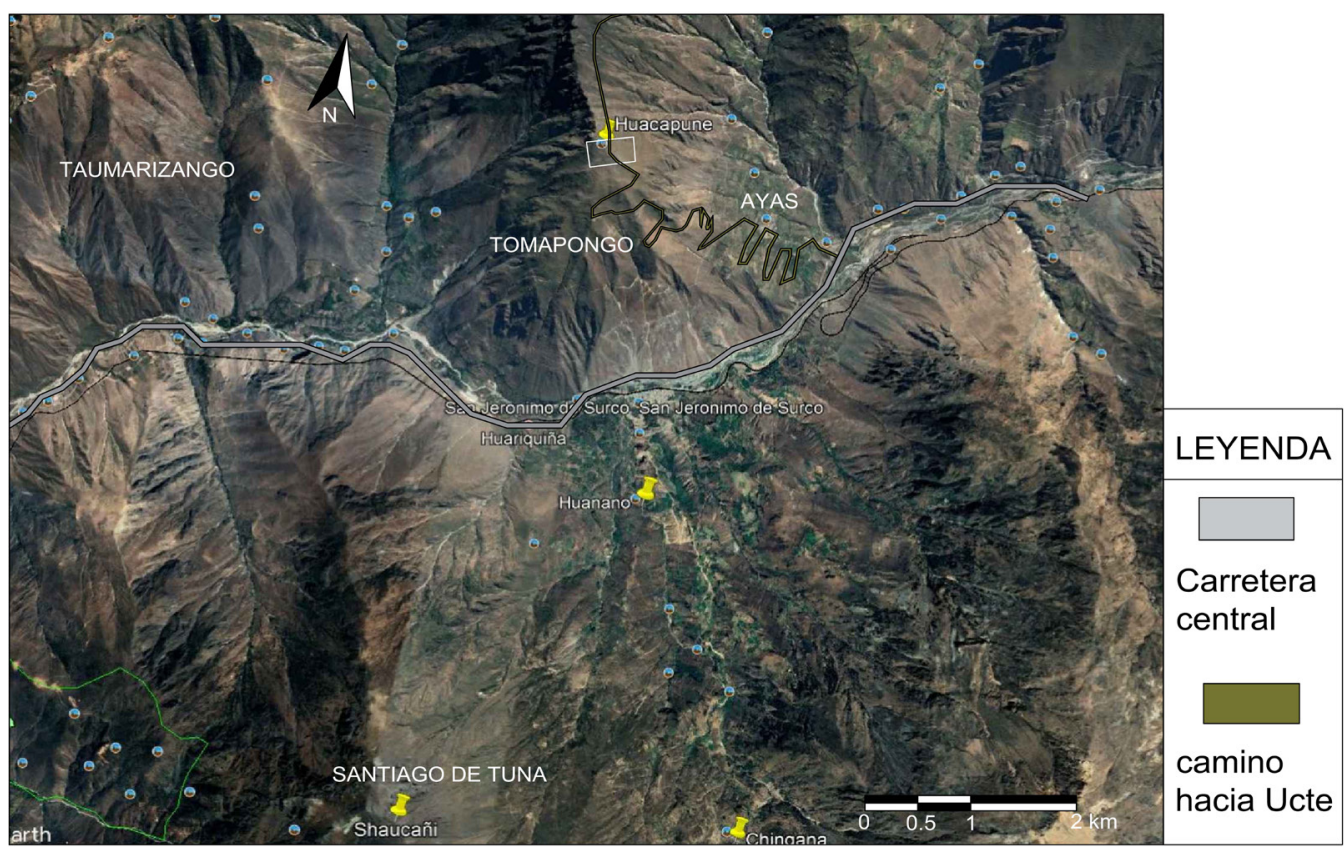

Figura 1. Posición espacial y acceso a Huacapune.

\section{APUNTES SOBRE LA GEOGRAFÍA HUMANA}

La visión arqueológica sobre la espacialidad en su enfoque procesual, el cual está más orientado al empirismo, la colocaba conjuntamente con la geografía como elementos restrictivos y determinantes los cuales influenciaban la trayectoria de las personas dentro de un espacio específico. Obviando en todo sentido la dimensión del pensamiento humano sobre su entorno y el poder que este posee para modificar el entorno geográfico y transformarlo en parte de la materialidad humana.

Este enfoque sobre la relación dicotómica y activa entre la naturaleza y el ser humano es conocida por ser parte del enfoque post-procesual, el cual da mayor importancia a la experiencia humana y en conjunto trata de desentrañar y entender el pensamiento humano tomando como prueba la construcción sintética que el ser humano crea en la naturaleza y las recurrencias en las funciones que el hombre otorga a los espacios. Estos temas son abordados por autores como Ian Hodder (Hodder y Orton, 1976).

Dentro de la corriente post-procesual la conocida arqueología del paisaje, es un enfoque que le da un nuevo sentido a la espacialidad, la cual propone como pivote al ser humano como ente principal que se relaciona con la geografía, la dota de un significado, es modificado y modifica esta con un fin (Anschuetz et al. 2001). 
Autores como Kurt Anschuetz, en una definición básica, coloca dentro de la arqueología del Paisaje tres aspectos generales: la ecología de los asentamientos, en la cual se estudia la relación entre la geografía y la estrategia que utiliza el humano para ordenarla, con el fin de localizar recursos económicos y de supervivencia dentro de una comunidad con un espacio definido.

El paisaje ritual por su parte, utiliza como base la etnografía de un territorio, y en base al registro de saberes míticos y la ancestralidad de una población, otorga a los espacios construidos un nuevo significado subjetivo, el cual es clave para entender como una población se adscribe a su territorio, ya que la población que erige un discurso sobre su arraigo mítico, tiende a reproducir rituales los cuales transmiten la idea de pertenencia. Esta visión es un complemento que puede ser utilizado en el dato duro arqueológico, de acuerdo a ella, en el estudio de la distribución espacial arquitectónica de un asentamiento, se debe tener en cuenta las acepciones cognitivas que el hombre le otorga a la arquitectura (Anschuetz et al. 2001).

El paisaje étnico está centrado en todos los rasgos culturales que engloba una comunidad y sobre estos en que espacio geográfico, tiempo y contextos son reproducidos para reconocer límites culturales, los cuales tienen su base en las llamadas "Áreas Culturales". Sin embargo, a diferencia de estas que tienen una visión regional, el paisaje étnico está más centrado en las diferencias de un área local.

En la materialidad arqueológica esto se puede expresar mediante los símbolos y las expresiones, que se plasman ya sean en recurrencias arquitectónicas, arte cerámico, geoglifos, petroglifos y por consiguiente, los contrastes que se pueden hallar en un espacio.

\section{ANTECEDENTES DE ESTUDIO EN LA ZONA}

Las primeras investigaciones a nivel arqueológico en la provincia de Huarochirí son abordadas y desarrolladas por el célebre huarochirano Julio C. Tello, el cual motivado por la gran incógnita que en su tiempo suponía Huarochirí, realizó un gran estudio en la meseta de Markawasi, junto a Próspero Miranda, titulada: "Huallallo, ceremonias gentilicias desarrolladas en la meseta cisandina del Perú. Distrito arqueológico de Casta" (Tello y Miranda, 1923). De la cual se pudo reconocer un sistema de ceremonias religiosas ancestrales y un gran conocimiento sobre los mitos de la zona.

En el año 1958, investigadores extranjeros llegaron al sitio arqueológico de Huaca-Puna (Huacapune) y realizaron un reconocimiento de la arquitectura del sitio, Bárbara Morford y David Stiglitz presentaron dicho estudio en la revista del Instituto Riva-Agüero (Morford y Stiglitz, 1969).

En el año 1974, bajo la dirección del entonces Instituto Nacional de Cultura (INC), se realiza un catastro de la zona del Rímac y Santa Eulalia, dirigido por el Arquitecto 
Carlos Milla Villena, el cual indexa la información relacionada a Huacapune, y lo relaciona a su hipótesis sobre el un territorio perteneciente a un grupo humano que se desarrolló durante el Periodo Intermedio Temprano. Más adelante, otras investigaciones que se centrarían en entender algunos sitios arqueológicos en el área, en base al desarrollo cultural local y su filiación cronológica, lo situaría al sitio en los periodos tardíos (Bueno, 1992).

Finalmente, recientes trabajos sobre Huacapune lo podemos encontrar en la revista Huarochirí Vol.1 (Mazzi, 2018) es una guía que nos da pautas sobre el complejo tema del paisaje sagrado Huarochirano, el cual poseía un panteón de deidades o camac (Bravo, 2018), las mismas que estaban adscritas a diferentes partes del territorio.

\section{EL PAISAJE RITUAL EN EL TERRITORIO DE HUAROCHIRÍ}

Dentro de la arqueología Peruana con este nuevo tópico abierto se hizo un gran aporte desde las investigaciones de la región Cuzco, la cual posee una relación (considerada sagrada) entre los sitios arqueológicos, el campo visual entre ellos, la relación entre los elementos geográficos y el agua, lo que extendió de manera significativa toda la información que se tiene sobre el fenómeno del paisaje sagrado en la arqueología Peruana, a través de los estudios sobre paisaje ritual, agua y ancestros en el sitio arqueológico de Ollantaytambo (Gose, 1996).

Otros estudios que ejemplifican el uso del enfoque ritual se encuentran en la sierra Norte en Huamachuco, por los trabajos realizados por Jhon y Theresa Topic, quienes tomaron indicadores de excavación, las crónicas del siglo XV y el estudio de la distribución arquitectónica del sitio Namanchugo para defender la hipótesis acerca del adoratorio de la deidad apu Catequil. Esto con base en la distribución de canales, la arquitectura, la geografía especial de la zona y las menciones históricas, lo que abrió un nuevo tema de investigación acerca de la funcionalidad ritual de los sitios arqueológicos y las pautas para poder identificarlos (Topic \& Topic, 2002).

Elárea de Huarochirí en la misma línea de investigación, se encuentra los trabajos realizados por el arqueólogo César Astuhuamán, quien, en el año 1997, realiza dos expediciones al nevado de Pariacaca, donde analiza la información recopilada en el manuscrito de Huarochirí, sobre los elementos geográficos especiales. Tomando como punto principal la comparación entre las citas textuales en el manuscrito en contraposición a los accidentes y elementos geográficos del nevado bajo la visión de la arqueología del paisaje sagrado y tomando como ejemplos otros lugares del Perú, así como comparaciones con oráculos de Grecia, en ese sentido, logra interpretar una relación entre el relato mítico con los elementos geográficos dentro del Escalerayoc, las pinturas rupestres de la zona y la franja de mármol 
que recorre el terreno el cual lo asocia con la leyenda del Amaru entre otros, con lo cual establece que el valor del relato mítico del poder de Pariaccaca fue tal, que incluso fue considerado como un apu de importancia para el Tawantinsuyo (Astuhuamán,1999).

\section{EL SITIO ARQUEOLÓGICO DE HUACAPUNE}

El sitio está conformado por un área nuclear que se define por la presencia de un conjunto de estructuras constituidas por una mampostería básicamente de pircas de piedra canteada con argamasa de barro, emplazados al pie de la cima de la montaña Tomapongo. En la parte llana central e inferior de este sitio, se ubica una gran área de planta triangular (figura 2) y una serie de recintos secundarios asociados a espacios menores que se integran a todo el conjunto mediante pasajes.

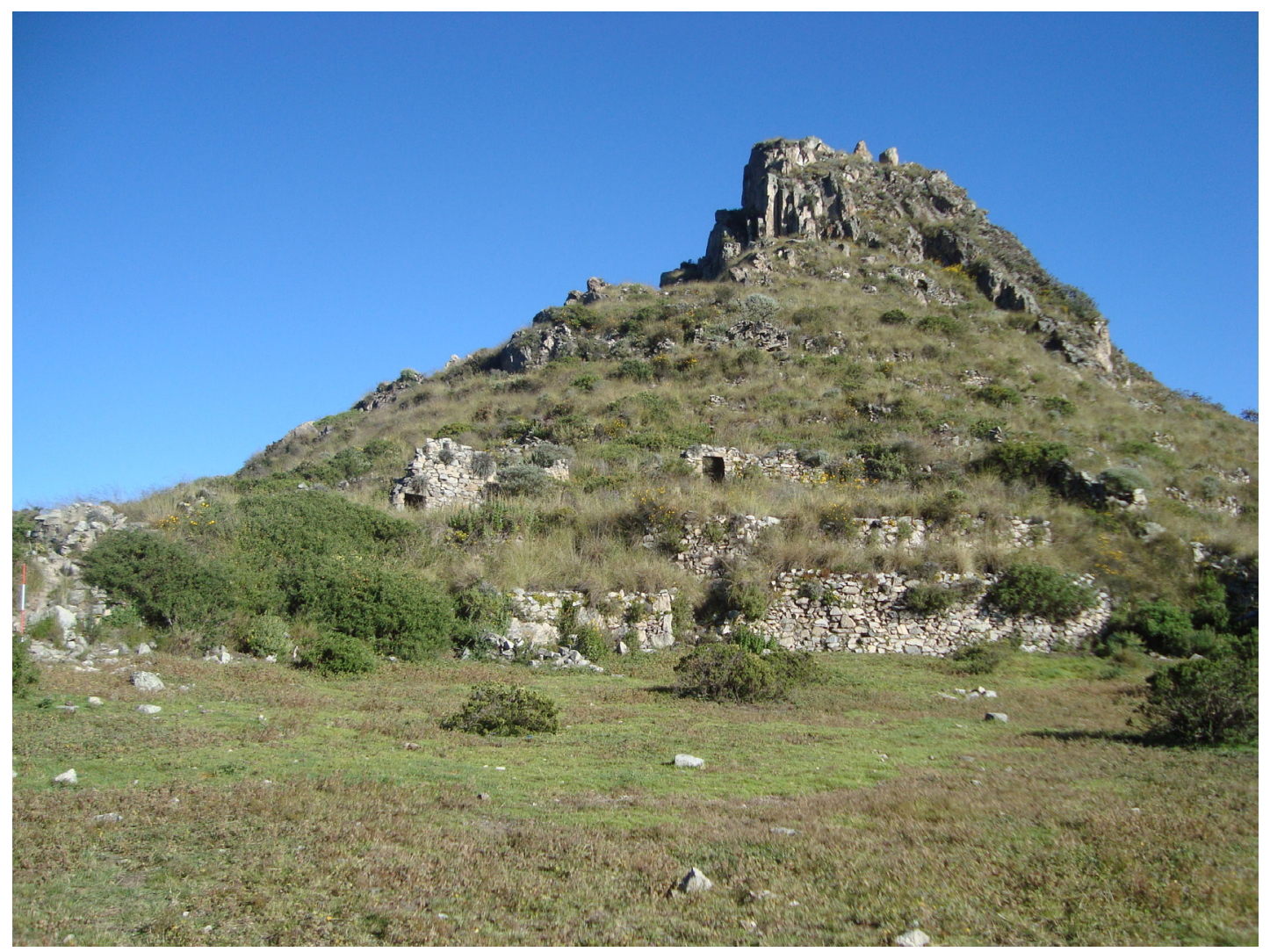

Figura 2. Plaza ubicada en la explanada de la primera plataforma. 


\section{EL SECTOR A - ANDENERÍA Y TERRAZAS}

Presencia de terrazas al sur este del sitio (figura 3) emplazadas en la ladera en posición alterna desde la mitad de la montaña hasta la cumbre del farallón. Cada una de estas terrazas presenta aparejo irregular y fueron elaborados de manera rústica. Las mismas fueron alimentadas por las escorrentías de agua provenientes del canal del lago Ucte.

\section{EL SECTOR B - PLATAFORMAS Y PLAZAS}

La plaza principal: está ubicado en una explanada de la primera plataforma al pie del promontorio rocoso en la cima de la montaña. Se define por un espacio plano de planta triangular obtenido por la construcción de muros de contención colocados aprovechando la pendiente. Allí confluye una de las principales calles norte-sur, camino que permiten el acceso y ascenso al sitio, asociado a un canal ubicado al este (figura 4). Hacia el noroeste se ubica una segunda plataforma, al cual se accede mediante peldaños laterales adosados al muro de $2 \mathrm{~m}$ de altura, que

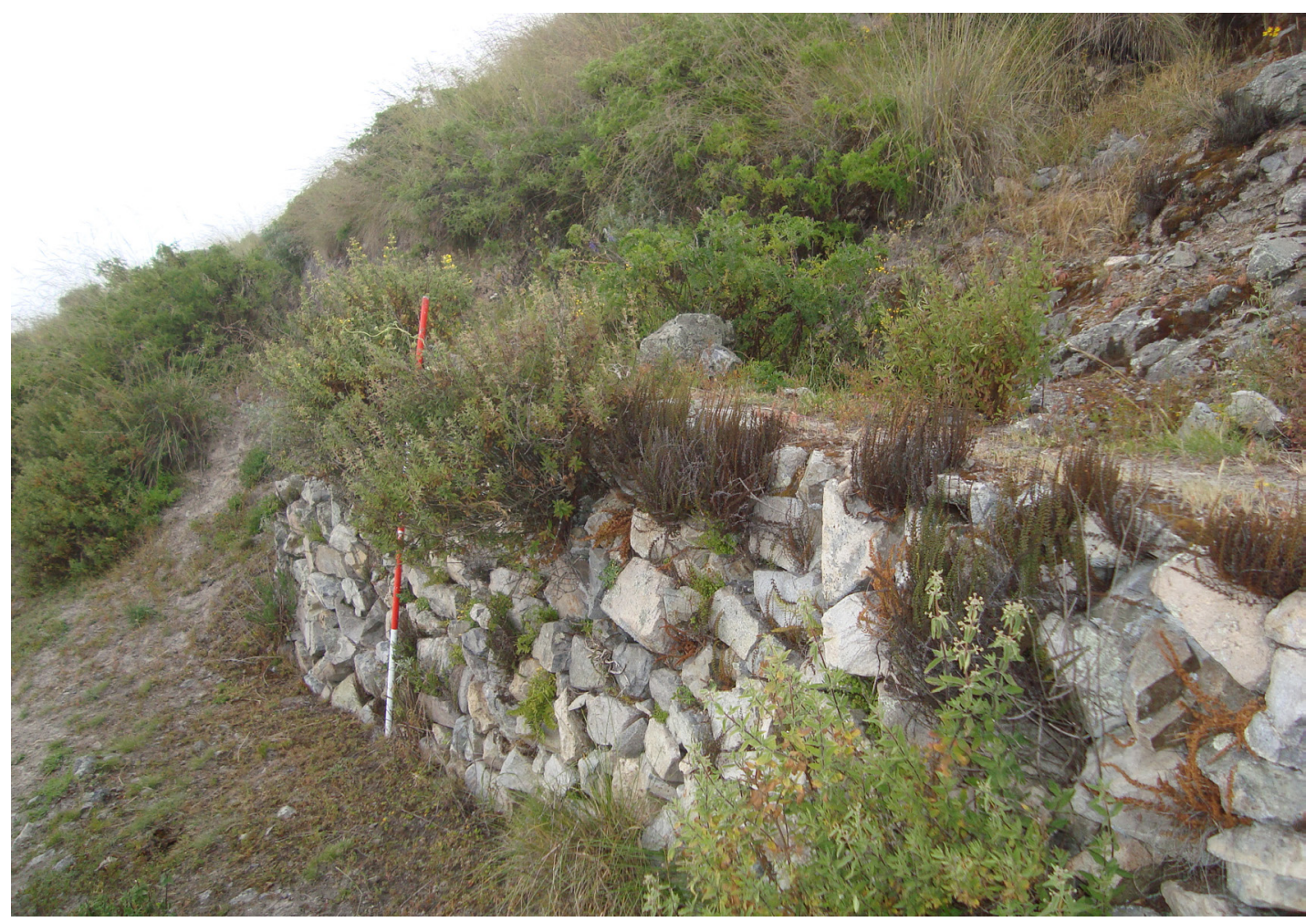

Figura 3. Terrazas de aparejo de piedra irregular a mitad del ascenso a la montaña Tomapongo. 


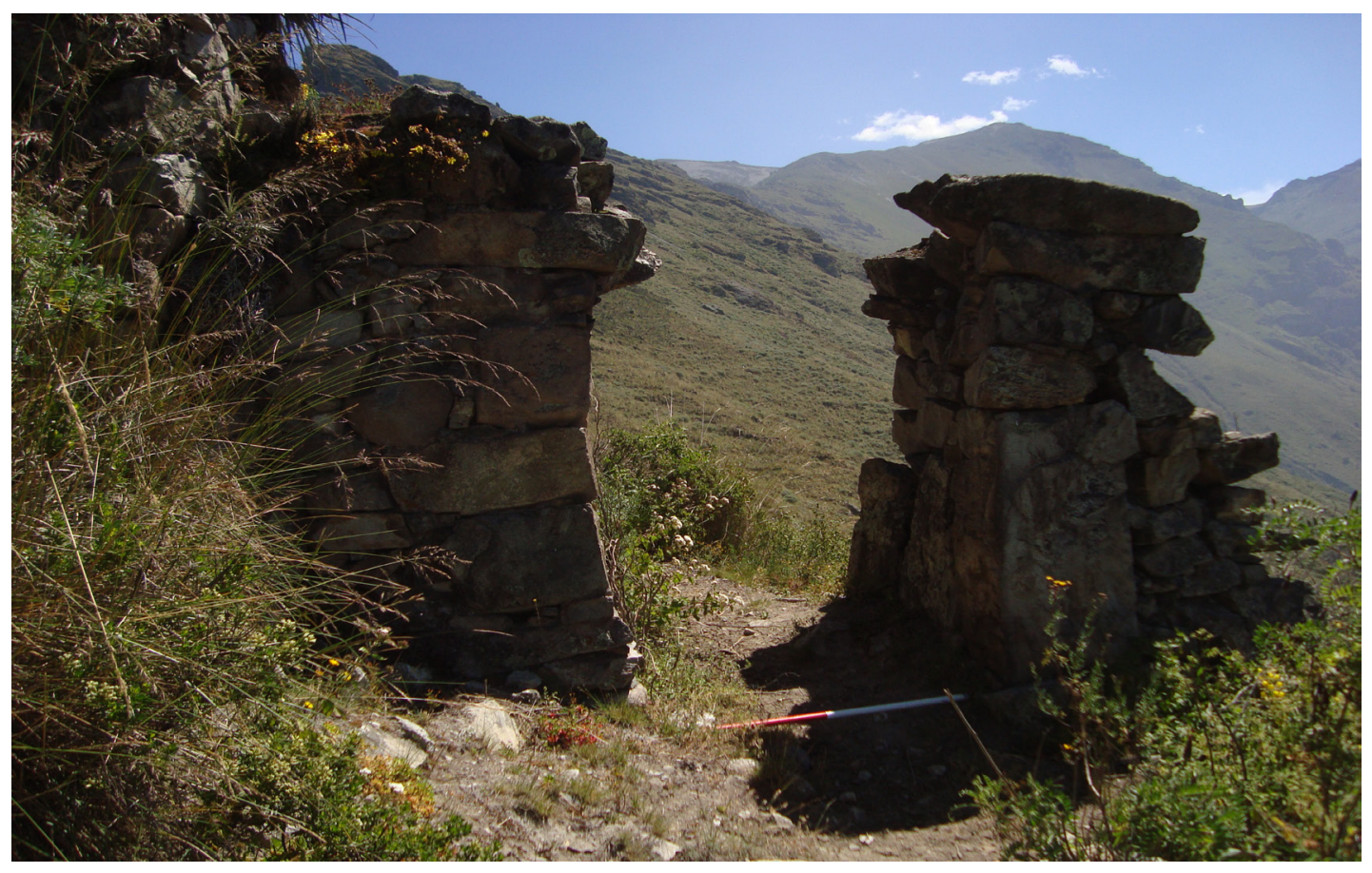

Figura 4. Acceso posterior de Huacapune en dirección N-E, hacia el sendero que conduce a la laguna de Ucte.

conducen a una plaza de menor tamaño de planta irregular y que se une mediante una calle de orientación oeste-este al sector C. Asimismo, al norte de esta plaza se ubica un vano de acceso rectangular pequeño (figura 5), a través del cual podemos dirigirnos a un nuevo acceso (figura 6) que conduce hacia una tercera plataforma donde se ubican recintos soterrados y patios asociados al promontorio rocoso.

\section{EL SECTOR C - RECINTOS Y PATIOS}

Los recintos de pequeñas cámaras de pisos soterrados de hasta 3 niveles con vanos de acceso de forma rectangular de $1 \mathrm{~m}$ de ancho por $1 \mathrm{~m}$ de alto (figura 7) y nichos de forma cuadrada y rectangular de aproximadamente $0.40 \mathrm{~m}$ por $0.30 \mathrm{~m}$ por lado (figura 8). Son estructuras de planta rectangular con esquinas redondeadas de 3 a 4 metros de lado aproximadamente con muros de $50 \mathrm{~cm}$ de ancho por 1.50 a 2 metros de alto (figura 9). Algunos recintos presentan voladizos de piedra que sobresalen de la parte superior de los paramentos tanto externos como internos. Dichas estructuras se comunican por pasadizos que a su vez se comunican con la plaza de la primera y la segunda plataforma. 


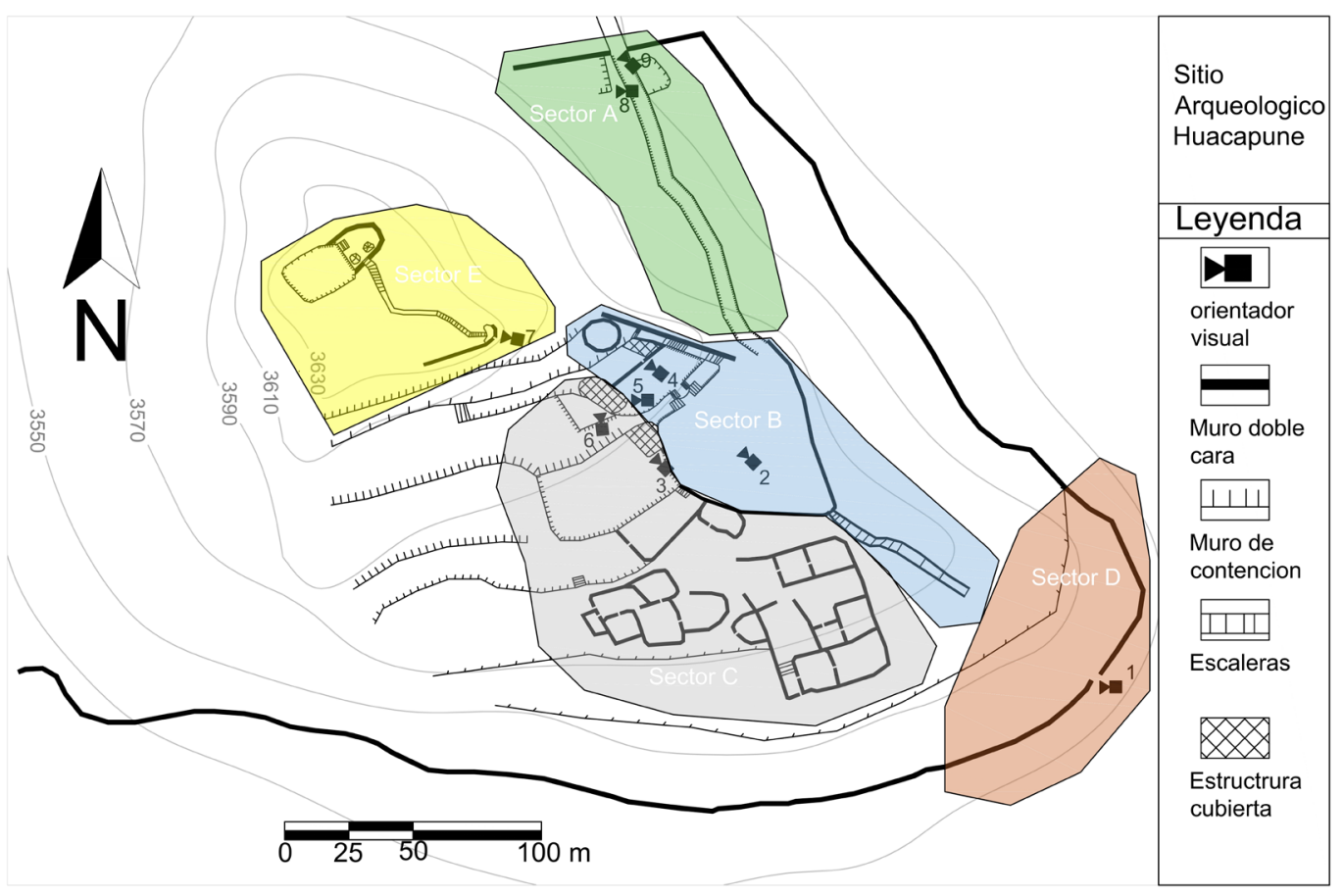

Figura 5. Sitio arqueológico de Huacapune. Los sectores señalados muestran áreas públicas (Sector A, B y D) y áreas privadas (Sector E y C)

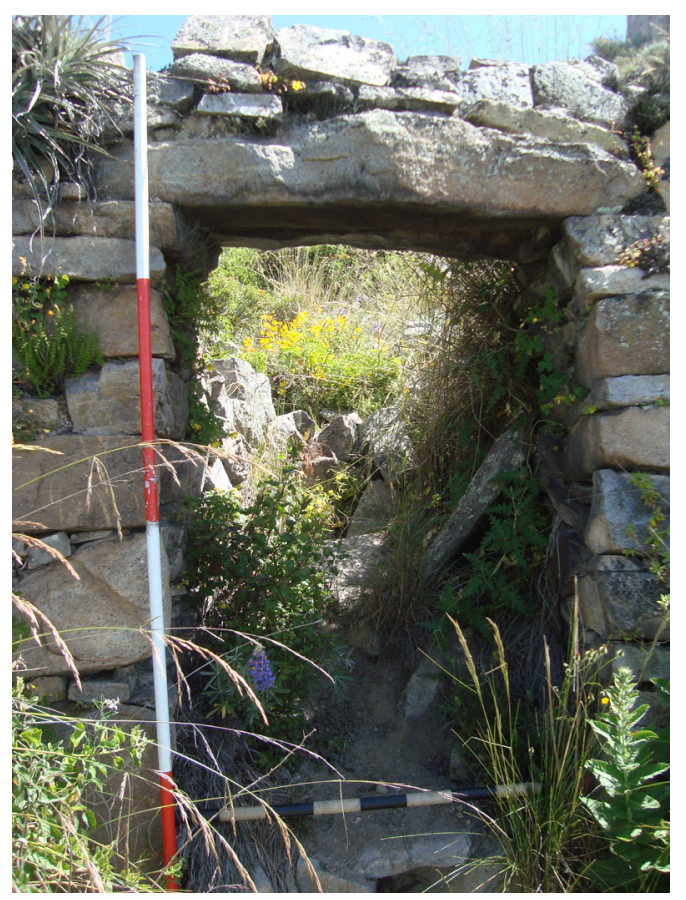

Figura 6. Vano de acceso a la tercera plataforma. 


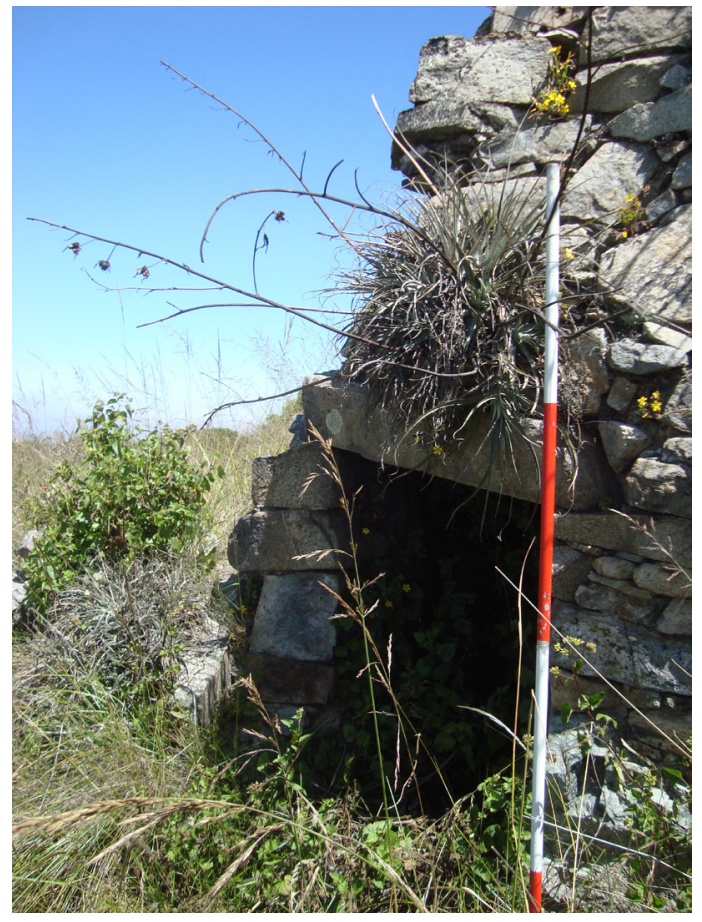

Figura 7. Vano de acceso a los recintos soterrados.

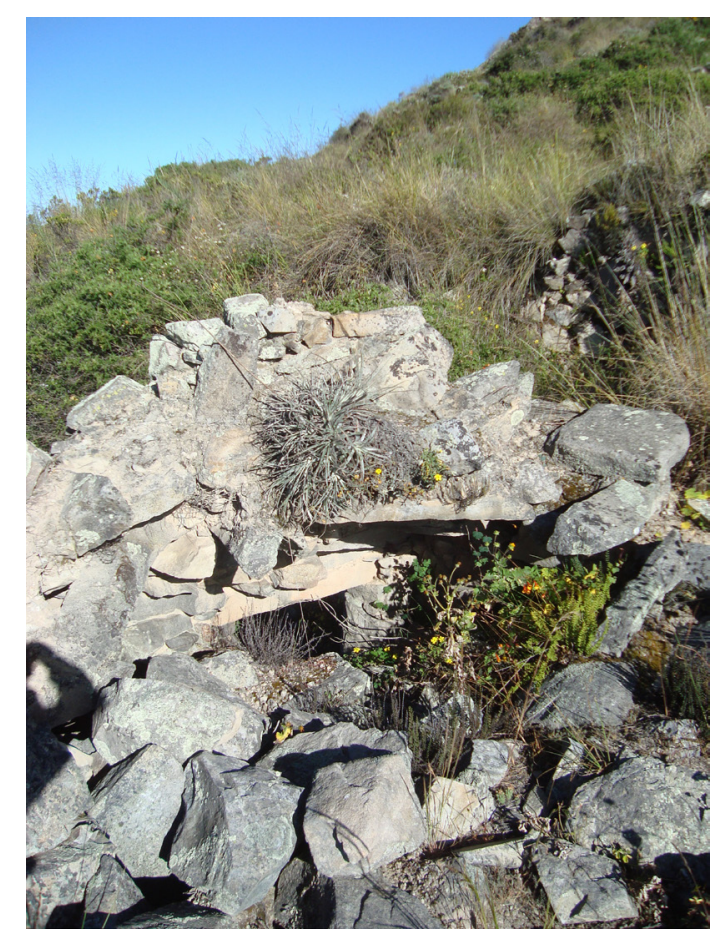

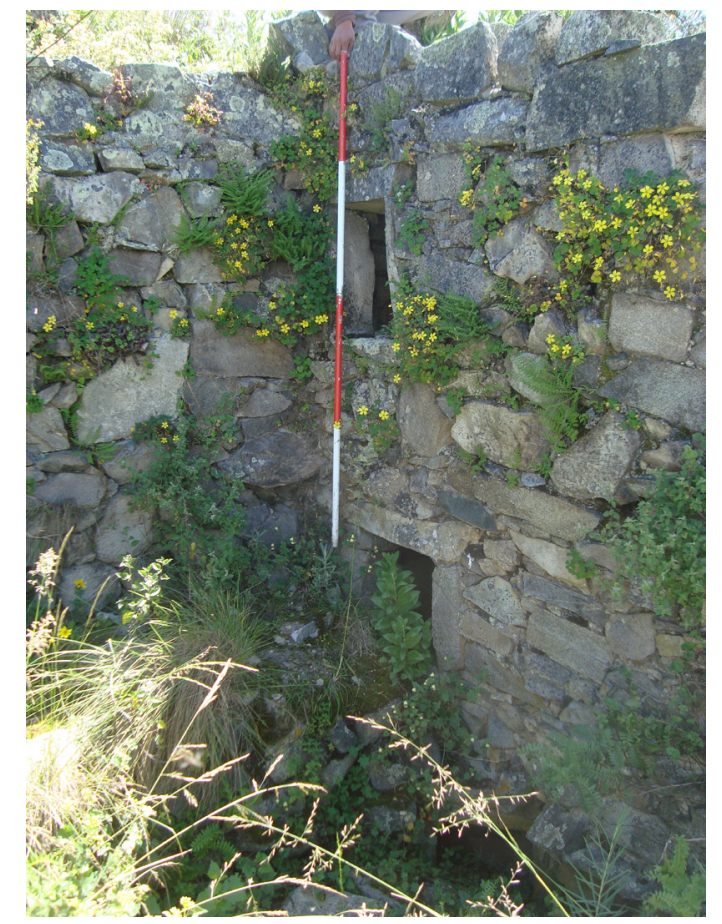

Figura 8. Nichos del paramento interno.

Figura 9. Detalle de estructura sin techo. 


\section{EL SECTOR D - INGRESO PRINCIPAL}

El acceso principal del sitio arqueológico Huacapune está conectado a través de un sendero simple, que llega a la muralla perimetral del sitio, la cual rodea todo el espacio entorno al sitio y lo separa del resto de la pendiente. La muralla principal posee una altura de $2.50 \mathrm{~m}$ y un ancho de $1.50 \mathrm{~m}$ en el lado S-E se puede apreciar la entrada principal del sitio, que es un acceso edificado con técnica simple de armado de piedras sin trabajar y con una forma similar al estilo de falsa bóveda (figura 10).

\section{EL SECTOR E-PROMONTORIO RO- coso}

Ubicada en la parte central y superior del sitio. Conformado por el promontorio rocoso, hacia el lado este de la roca principal hay varias construcciones de recintos de planta rectangular de accesos restringidos (figura 11), dichas estructuras están asociadas a una calle de dirección norte sur a la plaza de la primera plataforma. Desde la parte superior de la roca se tiene un magnífico control visual del sitio y de toda el área circundante a la montaña.

\section{DISCUSIONES}

\section{Sobre la arquitectura Huarochirana}

Dentro del territorio que comprende la actual Huarochirí, existen tecnologías y elementos arquitectónicos, que suelen ser observados con frecuencia. El primer caso que expusimos, se encuentra en el artículo publicado en el año 2018 "Deidades y culto al agua en Huarochirí: el caso de los centros ceremoniales o Kuris" (Mazzi 2018), el cual

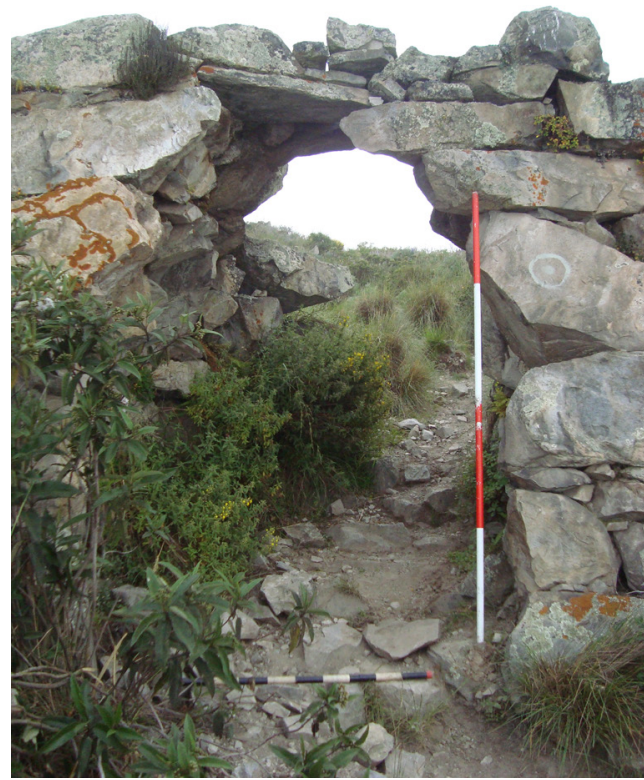

Figura 10. Acceso principal al sitio.

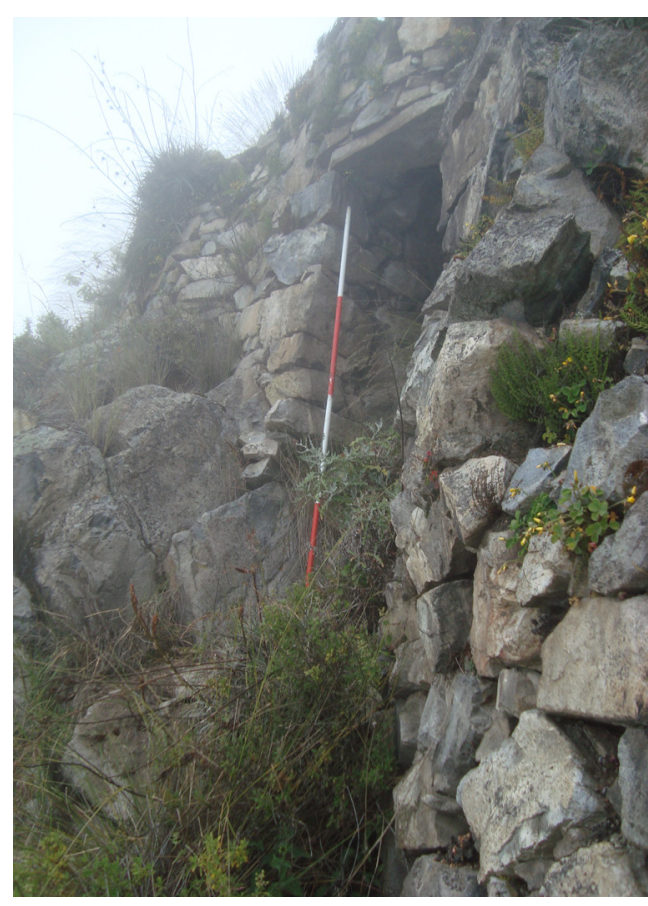

Figura 11. Detalle acceso principal hacia la cima del peñón. 
evidencia que los sitios en las cumbre que presentan peñascos, arquitectura compleja y elementos restrictivos, se encontraban asociados a la denominación Kuri, la cual fue enunciada por Julio C. Tello en 1923. Dentro de esta existen elementos arquitectónicos que se repiten dentro del territorio huarochirano, el primer caso son los portazgos de falsa bóveda, los cuales aparecen tanto en la zona norte de Huarochirí, como en la zona sur. Estos portazgos se encuentran asociados a los muros perimetrales que delimitan y restringen el acceso a los sitios arqueológicos. De igual manera, dentro de la arquitectura de esta denominación existen otros tipos de portazgos, los cuales poseen un gran trabajo en la piedra y se encuentran delimitando zonas internas.

Otro elemento importante es la arquitectura funeraria que se encuentra dentro de estos sitios, la cual, a diferencia del primer indicador, si varía en forma, denominación, función y tamaño. Dentro de todo el territorio arqueológico huarochirano se encuentra reportada la arquitectura funeraria conocida como la Chaukalla, la cual es un mausoleo de forma rectangular alargada, que posee 3 niveles verticales, siendo el primer nivel semisoterrado, conteniente de una gran cantidad de restos óseos humanos dispersos. Otra forma de arquitectura funeraria común son los mausoleos soterrados, conformado por estructuras sepultadas de forma cilíndrica, cubierto por un techo de lajas, los cuales contenían fardos funerarios.

El tercer elemento que está en asociación directa con la arquitectura, son los promontorios rocosos. Esta forma peculiar en la geografía es una constante que se repite para los sitios considerados Kuris, en la mayoría de los casos, estos peñones naturales han sido modificados con la construcción de escaleras y nivelación llana en su cima, en la cual se ha construido arquitectura, esta arquitectura por su restricción parece estar asociada a funciones rituales.

\section{EN RELACIÓN AL PAISAJE SAGRADO DE LA ZONA DE HUACAPUNE}

Ya establecida la orientación espacial de la arquitectura de Huacapune, la cual está pensada para resaltar la visión del peñón, podemos hacer un recuento sobre el paisaje sagrado circundante a Huacapune. Dentro del amplio campo visual de la plaza principal de Huacapune hacia el sur, podemos observar 5 sitios arqueológicos, desde el SO en la parte alta de los picos donde se encuentra el distrito de San Andrés de Tupicocha, se puede observar del pico principal el sitio arqueológico Shaucañi ${ }^{1}$, siguiendo del SO al SE, se puede observar en la parte baja de San Jerónimo de Surco el sitio arqueológico de Huanano y Chingana (figura 12), finalmente hacia la zona de Matucana (figura 13) se puede apreciar parte del sitio arqueológico de Pariasune y Punsho Pukro².

\footnotetext{
1. Información obtenida por conversaciones con el bachiller en Arqueología de la UNMSM Bradymir Bravo Meza, sobre sus investigaciones preliminares en la zona de San Andrés de Tupicocha.

2. Información obtenida por conversaciones con el bachiller en Arqueología de la UNFV Rodrigo Padilla Sinchi, sobre sus investigaciones preliminares en la zona de Matucana.
} 
Cuadro comparativo de la arquitectura en Huarochirí

\begin{tabular}{|c|c|c|c|c|c|c|c|}
\hline \multicolumn{8}{|c|}{ ADORATORIOS DE ALTURA EN LA SIERRA DE LIMA } \\
\hline \multicolumn{5}{|c|}{ MARGEN IZQUIERDA } & \multicolumn{3}{|c|}{ MARGEN DERECHA } \\
\hline SITIOS & LLACSATAMBO & SUNI & $\begin{array}{l}\text { PUEBLO VIEJO } \\
\text { DE PILAS }\end{array}$ & ANSHAHUAY & HUACAPUNE & WARICHACA & $\begin{array}{l}\text { TEMPLO DE } \\
\text { WALLALLO }\end{array}$ \\
\hline \multirow{9}{*}{$\begin{array}{l}\text { TIPOS DE } \\
\text { ESTRUCTURAS }\end{array}$} & Chullpas & Chullpas & Chullpas & Chullpas & Chullpas & Chullpas & Chullpas \\
\hline & $\begin{array}{l}\text { Circulares } \\
\text { subterráneos }\end{array}$ & Viviendas & Viviendas & Viviendas & $\begin{array}{l}\text { Circulares } \\
\text { subterráneos }\end{array}$ & $\begin{array}{l}\text { Circulares } \\
\text { subterráneos }\end{array}$ & Viviendas \\
\hline & Viviendas & $\begin{array}{l}\text { Promonto- } \\
\text { rios }\end{array}$ & Plazas & Plazas & Viviendas & Viviendas & Muros \\
\hline & Plazas & Pasadizos & Muros & Muros & Plazas & Plazas & Promontorios \\
\hline & Muros & $\begin{array}{l}\text { Canales y } \\
\text { andenes }\end{array}$ & Pasadizos & $\begin{array}{l}\text { Promonto- } \\
\text { rios }\end{array}$ & Muros & Muros & Pasadizos \\
\hline & Promontorios & & & Pasadizos & $\begin{array}{l}\text { Promonto- } \\
\text { rios }\end{array}$ & Promontorios & Huanca \\
\hline & $\begin{array}{l}\text { Canales y } \\
\text { andenes }\end{array}$ & & & Huanca & Pasadizos & Pasadizos & Canal \\
\hline & & & & $\begin{array}{l}\text { Canales y } \\
\text { andenes }\end{array}$ & Huanca & Huanca & \\
\hline & & & & & $\begin{array}{l}\text { Canales y } \\
\text { andenes }\end{array}$ & Canal & \\
\hline $\begin{array}{l}\text { TIPOS DE } \\
\text { ACCESOS }\end{array}$ & $\begin{array}{l}\text { Dintel } \\
\text { Falsa bóveda }\end{array}$ & $\begin{array}{l}\text { Dintel } \\
\text { otros }\end{array}$ & $\begin{array}{l}\text { Dintel } \\
\text { Falsa bóveda }\end{array}$ & $\begin{array}{l}\text { Dintel } \\
\text { Falsa bóveda }\end{array}$ & Dintel & $\begin{array}{l}\text { Dintel } \\
\text { Falsa bóveda }\end{array}$ & Dintel \\
\hline \multirow{4}{*}{$\begin{array}{l}\text { CALIDAD DE } \\
\text { TRABAJO DE } \\
\text { MATERIALES }\end{array}$} & $\begin{array}{l}\text { Piedra } \\
\text { desbastada }\end{array}$ & $\begin{array}{l}\text { Piedra } \\
\text { desbastada }\end{array}$ & $\begin{array}{l}\text { Piedra can- } \\
\text { teada }\end{array}$ & $\begin{array}{l}\text { Piedra } \\
\text { canteada }\end{array}$ & $\begin{array}{l}\text { Piedra } \\
\text { desbastada }\end{array}$ & Piedra canteada & Piedra labrada \\
\hline & $\begin{array}{l}\text { Piedra can- } \\
\text { teada }\end{array}$ & $\begin{array}{l}\text { Piedra can- } \\
\text { teada }\end{array}$ & $\begin{array}{l}\text { Piedra } \\
\text { labrada }\end{array}$ & $\begin{array}{l}\text { Piedra } \\
\text { labrada }\end{array}$ & $\begin{array}{l}\text { Piedra can- } \\
\text { teada }\end{array}$ & Piedra labrada & $\begin{array}{l}\text { Uso de mam- } \\
\text { postería }\end{array}$ \\
\hline & $\begin{array}{l}\text { Piedra la- } \\
\text { brada }\end{array}$ & $\begin{array}{l}\text { Uso de } \\
\text { mampostería }\end{array}$ & $\begin{array}{l}\text { Uso de } \\
\text { mampostería }\end{array}$ & $\begin{array}{l}\text { Uso de } \\
\text { mampostería }\end{array}$ & $\begin{array}{l}\text { Piedra la- } \\
\text { brada }\end{array}$ & $\begin{array}{l}\text { Uso de } \\
\text { mampostería }\end{array}$ & \\
\hline & & & & & $\begin{array}{l}\text { Uso de mam- } \\
\text { postería }\end{array}$ & & \\
\hline \multirow[b]{2}{*}{ NOTAS } & $\begin{array}{l}\text { Las chullpas } \\
\text { presentan } 3 \\
\text { niveles }\end{array}$ & \multirow[b]{2}{*}{$\begin{array}{l}\text { Presenta } \\
\text { pinturas } \\
\text { ruprestres }\end{array}$} & \multirow[b]{2}{*}{$\begin{array}{l}\text { Sitio transi- } \\
\text { cional Yau- } \\
\text { yo - Inca }\end{array}$} & \multirow[b]{2}{*}{$\begin{array}{l}\text { Uso de } 3 \\
\text { promonto- } \\
\text { rios rocosos }\end{array}$} & $\begin{array}{l}\text { Uso de } 3 \\
\text { muros peri- } \\
\text { métrico }\end{array}$ & \multirow[b]{2}{*}{$\begin{array}{l}\text { Huella de felino } \\
\text { en bajo relieve }\end{array}$} & \multirow[b]{2}{*}{$\begin{array}{l}\text { Escalera es- } \\
\text { culpida hacia } \\
\text { el promon- } \\
\text { torio }\end{array}$} \\
\hline & $\begin{array}{l}\text { En las } \\
\text { ventanas de } \\
\text { las chullpas } \\
\text { se aprecian } \\
\text { cornisas hori- } \\
\text { zontales }\end{array}$ & & & & $\begin{array}{l}\text { Escalera es- } \\
\text { culpida hacia } \\
\text { el promon- } \\
\text { torio }\end{array}$ & & \\
\hline \multirow{2}{*}{$\begin{array}{l}\text { DATOS GEO- } \\
\text { GRÁFICOS }\end{array}$} & $\begin{array}{l}\text { Provincia de } \\
\text { Huarochiri }\end{array}$ & $\begin{array}{l}\text { Provincia } \\
\text { de Huaro- } \\
\text { chiri }\end{array}$ & Asia- Omas & $\begin{array}{l}\text { San Lorenzo } \\
\text { de Quinti }\end{array}$ & $\begin{array}{l}\text { San Jerónimo } \\
\text { se Surco }\end{array}$ & $\begin{array}{l}\text { San Mateo de } \\
\text { Otao }\end{array}$ & Markawasi \\
\hline & $\begin{array}{l}3698 \\
\text { m s.n.m. }\end{array}$ & $\begin{array}{l}3698 \\
\text { m s.n.m. }\end{array}$ & $\begin{array}{l}3264 \\
\text { m s.n.m. }\end{array}$ & $\begin{array}{l}3580 \\
\text { m s.n.m. }\end{array}$ & $\begin{array}{l}3560 \\
\text { m s.n.m. }\end{array}$ & $\begin{array}{l}3880 \\
\text { m s.n.m. }\end{array}$ & $\begin{array}{l}3520 \\
\text { m s.n.m. }\end{array}$ \\
\hline
\end{tabular}




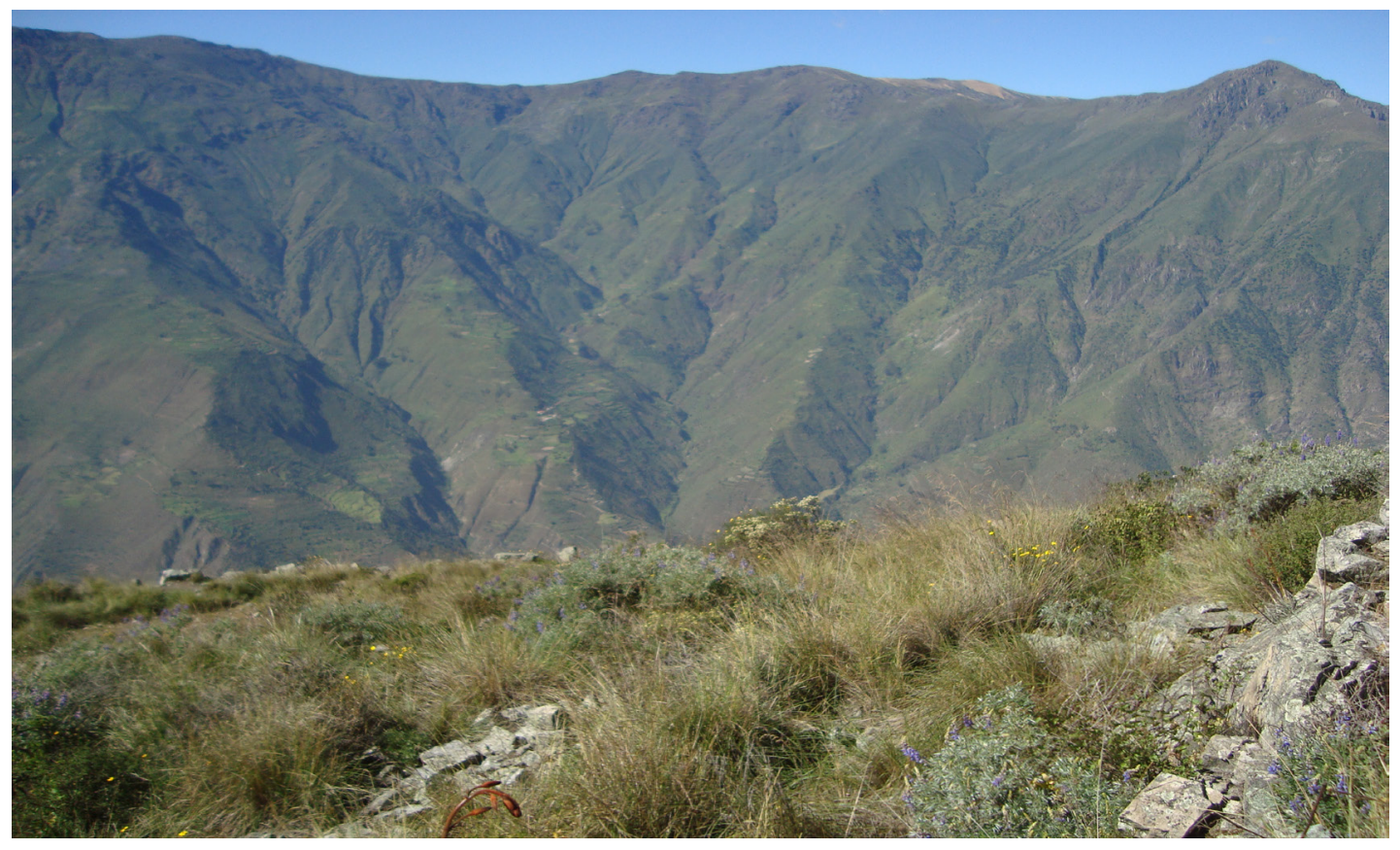

Figura 12. Vista del sitio arqueológico Shaucañi (extremo derecho), Huanano (parte baja) y Chingana (parte alta)

Nuestra interpretación acerca del significado de esta relación visual inter-sitios corresponde a la idea del espacio abstracto el cual estuvo bajo la tutela de los camac (Bravo, 2018). Como lo explicaron en sus estudio Julio C. Tello y Taylor en el manuscrito de Huarochiri, cada comunidad circunscrita a un espacio físico, tendía a constantes alianzas y conflictos, estos motivados dentro de su cosmología, por eventos significativos para poder reproducir el ciclo agrario, es decir; cada comunidad huarochirana - la cual necesariamente tuvo que adscribirse a un arraigo mítico para poder establecer una identidad propia-, tuvo épocas en donde tuvo que pedir ayuda a otra comunidad y su camac tutelar para poder atraer a la lluvia y la buena cosecha, o por el contrario en otro momento a su comunidad le sucedieron desgracias por la inacción de su camac y el ataque frontal de otro camac. Estos eventos están descritos por Taylor (1999) en el pasaje:

"Los surco prefieren que sean los Huayllas quienes bailen...cualquiera de estos Huayllas que reside en surco cuando viene a comprar coca a suquiacancha pide a la vendedora que aumente su porción por ser el huacsa...Hoy en día aprovechan la ocasión de cualquier pascua importante de los cristianos para celebrar esta pascua y ejecutar estos bailes; y la gente de surco aventaja a todas las otras comunidades..." (p. 131). 


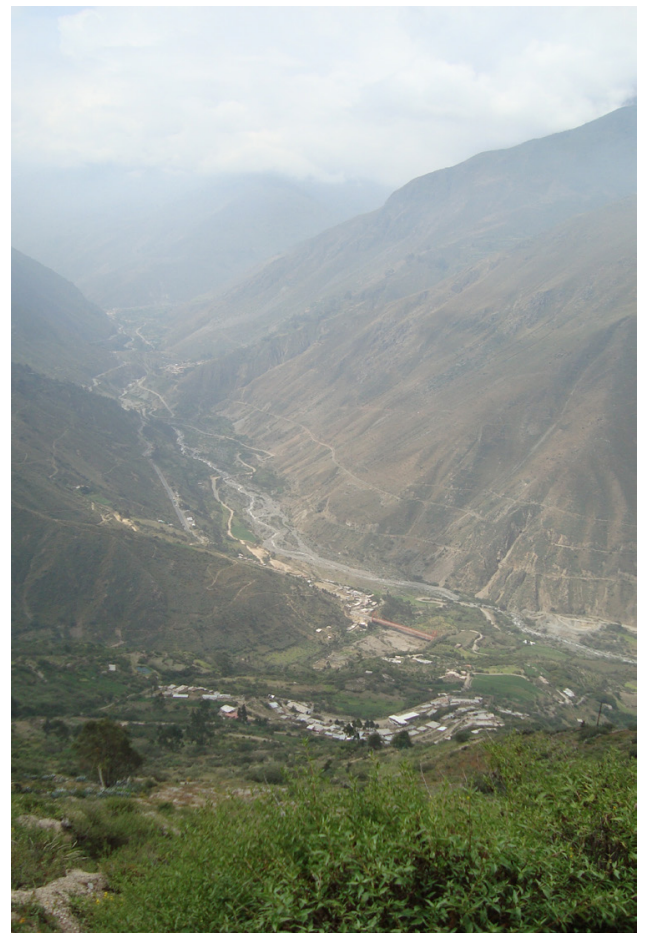

Figura 13. Vista desde Huacapune del sitio arqueológico Pariasune (abajo) y Punsho Pukro (arriba).

Tomando como ejemplo la comunidad de San Jeronimo de Surco la cual posiblemente tuvo como camac tutelar a Vilcacoto, realiza un gesto ceremonial con la comunidad vecina de Suquiacancha (San Bartolomé), realizando un trueque por coca para la ceremonia hacia Vilcacoto. Por otro lado, los conflictos entre los camac de Huarochiri están documentados en varios pasajes, entre los más conocidos están las luchas entre Wallallo Carhuancho y Pariaccaca, tras ellas, van dejando eventos considerados como cataclismos. Otros pasajes dentro del trabajo de Tello describen la espinosa relación entre el camac Wallallo y sus vecinos, Wampu y Makas, los cuales de manera simbólica roban la fertilidad de Wallallo (Gónadas) y la ocultan en otra región, creando así desgracias para la comunidad de Markawasi, que sufrió sequias y malas cosechas por la ausencia de su camac.

Entonces, nuestra posición respecto a que camac era el tutelar del cerro Tomapongo, nos inclina a deducir que fue el camac Makas. Si dentro de la geografía abstracta retratamos los espacios adscritos a los camac mencionados, podemos darnos cuenta que el territorio circundante a Markawasi hacia el N-O está representado por la comunidad de Chaclla hacia la otro margen de la cordillera, esta comunidad está representada por el camac Wampu. De la misma manera hacia el S-E se encuentra la comunidad de Otao, la cual al parecer estuvo representada por el camac Makas; sin embargo, resaltamos que la comunidad de Otao presenta un sendero prehispánico 
que conecta sitios de la meseta de Canchacalla, Taumarizango y Tomapongo, por lo cual es plausible que estas 3 comunidades estuvieran bajo la tutela de Makas al estar conectadas por una red vial interna (figura 14).

\section{CONCLUSIONES}

El sitio arqueológico de Huacapune es la parte principal dentro de un sistema de asentamientos que se emplazan en el cerro Tomapongo, posee una arquitectura distintiva, que resalta por el minucioso acabado de la piedra, las restricciones en sus recintos y todo el esfuerzo dedicado a la modificación del peñón, esto nos indica que estuvo pensado para ser un lugar donde se realizaban acciones relacionadas con las practicas rituales. Tales prácticas, las cuales fueron retratadas por Julio C. Tello en la meseta de Markawasi, nos da a entender que estos sitios están relacionados al tema de la fertilidad, las lluvias y la conexión de estas necesidades fundamentales, con lo holístico y sobrenatural, ya que estas necesidades para el pueblo Huarochirano son

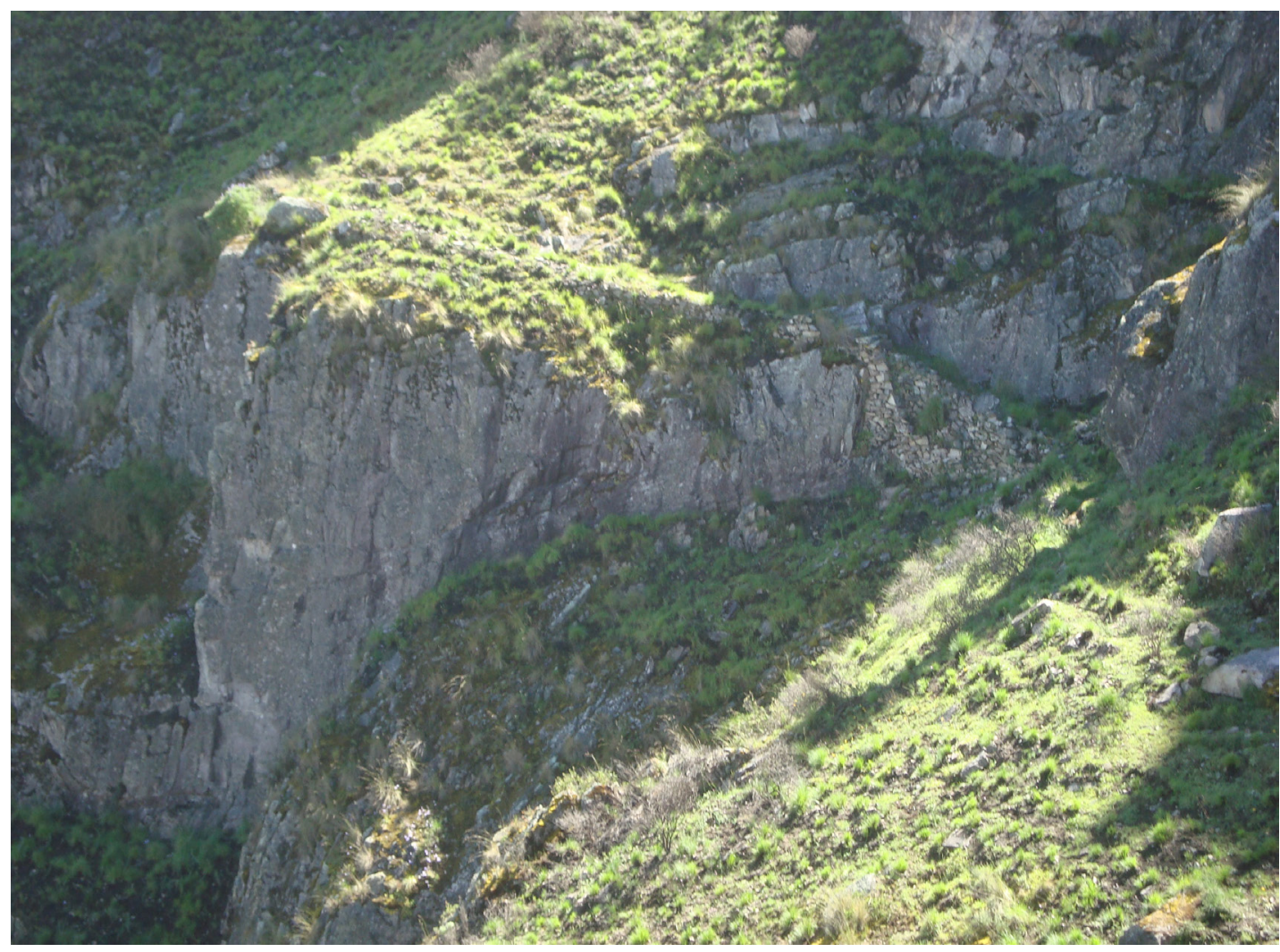

Figura 14. Camino de Herradura ubicado al norte de Huacapune, que comunica con San Mateo de Otao. 
obra de las deidades o camacs, los cuales pueden atender o desatender el llamado de los pobladores y por lo tanto causar una reacción a favor o en contra de cada comunidad adscrita a la tutela del camac.

Sin embargo, dentro de este trabajo quedan algunos cabos sueltos, quizá en el futuro con más información por crearse, pueda darnos una mejor visión sobre temas que nos falta mencionar.

El primer punto que aún no podemos visualizar en su dimensión completa, es la etapa mítica final donde el apu Pariaccaca por la agencia del Tawatinsuyo se vuelve el apu tutelar de todo Huarochiri. Ya que no existe una simbología o un formato arqueológico el cual nos indique que el camac tutelar Makas fuera reemplazado por Pariacacca y por lo tanto durante los periodos tardíos se hubiera rendido homenaje y favores a este apu.

Otro punto el cual aún no podemos dilucidar por falta de pruebas en superficie es el tema de la cronología plasmada en la materialidad. Ya que la arquitectura de Huacapune es análoga en otras áreas de Huarochiri, no es un indicador del todo fiable para establecer una cronología, que solo podrá ser corroborada con trabajos de excavación los cuales puedan darnos datos fiables sobre procesos arqueológicos, por otro lado, la falta de tiestos cerámicos en superficie, que indique una simbología o arte con la cual se pueda asociar una cronología, fue en su mayoría escasa, por lo cual no es del todo fiable enunciar aun una cronología.

Agradecimientos: Quisiéramos agradecer al Mg. Daniel Morales, por la orientación en la investigación, consejos y compartir su experiencia, asimismo, un agradecimiento especial a los arqueólogos y compañeros Oscar Maldonado, Luis Muchari y Sergio Sáez, por el apoyo en la culminación de los planos y dibujos realizados en campo. Finalmente, agradecemos al grupo de estudios interdisciplinarios Caqui, de quienes sus miembros los bachilleres Bradymir Bravo y Rodrigo Padilla nos revelaron un panorama más amplio sobre la arqueología de la cuenca alta de Huarochirí.

\section{REFERENCIAS BIBLIOGRÁFICAS}

Anschuetz, K. et al. (2001). Una arqueología de los paisajes: perspectivas y tendencias. Journal of Archoeological Research, 9(2), 152-197. USA.

Astuhuamán, C. (1999). El Santuario de Pariacaca, Alma Mater. Revista de Investigación de la Universidad Nacional Mayor de San Marcos, (17), 127-147. Lima

Bueno, A. (1992). Arqueología de Huarochirí. En Huarochirí: ocho mil años de historia. Tomo I (pp. 13-62.). Municipalidad de Santa Eulalia de Acopaya, Huarochirí Lima. 
Bravo, B. (2018). El derrotero de los Camac en Huarochirí: de Mama a la tierra de los Sutca de San Andres de Tupicocha. Huarochiri Vol.1. El Champal de Cocachacra (notas). 54-88.

Hodder, I. y Orton, C. (1976). Spatial analysis in Archaeology. Cambridge University Press. USA.

Mazzi, L. (2018). Deidades y culto al agua en Huarochirí: el caso de los centros ceremoniales Kuris. Huarochiri Vol.1. El Champal de Cocachacra (notas). 42-53.

Milla, C. (1974). Inventario y Catastro del valle del Rímac y Santa Eulalia. Instituto Nacional de Cultura, Centro de Investigación y Restauración de Bienes Monumentales, Lima.

Morford, B. y Stiglitz, J. (1969). Ruinas de Huaca-Puna (primer sector). Boletín del seminario de arqueología, Instituto Riva-Agüero (4), 65-72. Pontificia Universidad Católica del Perú.

Taylor, G. (1999). Ritos y tradiciones de Huarochirí. Instituto Francés de Estudios Andinos - Lluvia. Editores. Lima-Perú.

Tello, J y Miranda, P. (1923). Wallallo. Ceremonias gentílicas realizadas en la región cisandina del Perú central (distrito arqueológico de Casta). Inca. Revista trimestral de estudios antropológicos, 1(2), 475-549.

Topic, J \& Topic T y Melly, A. (2002). Catequil: The Archaeology, Ethnohistory and Ethnography of a Major Provincial Huaca. En William H. Isbell y Helaine Silverman (Eds.). Andean Archaeology I: Variations in Sociopolitical Organization (pp. 303-336.). New York: Kluwer Academic-Plenum Press.

Villar, P. (1982). Arqueología del departamento de Lima. Segunda Edición, Atusparia Ediciones, Lima 


\section{SOBRE LOS AUTORES}

\section{Luigi Mazzi Pflucker}

Bachiller en Ciencias Sociales en la especialidad de arqueología por parte de la Universidad Nacional Mayor de San Marcos. Se ha desempeñado como arqueólogo responsable del análisis, ordenamiento y clasificación de la colección Arturo Jiménez Borja AJB-Puruchuco, recientemente director de campo del Proyecto de Investigación Arqueológica PIA Cashahuacra Alta 2018 (RD 269/ VMCIC/ DGPA/ MC).

\section{José Antonio Bazán Castillo}

Bachiller en Ciencias Sociales, licenciado en Arqueología por la Universidad Nacional Mayor de San Marcos con Diplomado de Gestión Cultural por la Universidad Antonio Ruiz de Montoya, se ha desempeñado como arqueólogo de campo en el proyecto de investigación arqueológica Zona Arqueológica Caral, recientemente formó parte del proyecto de investigación arqueológica Fortaleza de Campoy y actualmente viene laborando en el Sector Privado con SACRUN S.A.C diversas intervenciones en el Área Sur Andina y forma parte del grupo de investigación del Instituto de Cultura, Historia y Medio Ambiente ICHMA. 